\title{
Jesús soto e o conhecimento científico: um encontro criador entre o racional, o empírico e 0 artístico
}

\author{
MARIELA BRAZÓN HERNÁNDEZ
}

Resumo

Este artigo aborda de maneira sintética a identificação, análise e compreensão das relações existentes entre a obra do artista Jesús Soto - pioneiro da arte cinética - e o pensamento científico contemporâneo, especificamente as teorias físicas e matemáticas que revolucionaram o estudo do mundo físico, correspondentes às primeiras décadas do século XX. A produção de Soto pode ser vista como uma complexa rede de problemas/soluções que interagem ao longo do tempo e do espaço, alimentando a formulação de novas questões e a busca dinâmica de respostas, tanto na área da criação artística como na da teoria do conhecimento.

Palavras-chave: Arte e ciência, arte e epistemologia, Jesús Soto 


\title{
Jesús Soto and the scientific knowledge: a creative encounter between the rational, the empirical and the artistic
}

MARIELA BRAZÓN HERNÁNDEZ

\begin{abstract}
This article deals, in a condensed way, with the identification, the analysis and the comprehension of the relations between the work of artist Jesús Soto - pioneer of the kinetic art - and the contemporary scientific thinking, specially the physical and mathematical theories that revolutionized the study of the physical world in the first decades of $2 \mathrm{O}^{\text {th }}$ century. Soto's production can be seen as a complex network of problems/solutions that interact along time and space, stimulating the formulation of new questions and the dynamic search for answers in the area of the artistic creation and within the theory of knowledge.
\end{abstract} epistemology, Jesús Soto 


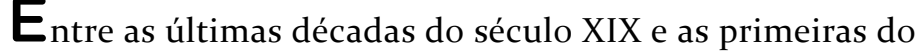
século XX, o homem foi testemunha de mudanças radicais na compreensão da realidade física. Surgiu a ideia de campo, que além de explicar as misteriosas ações à distância entre os corpos, apresentava o espaço como um ente pleno e ativo. Foi confirmada a natureza dual da luz - radiação que se manifesta ora como onda, ora como partícula - e foi aceito que ambas as expressões são estados do universo eletromagnético que, longe de se confrontarem, se complementam. Derrubou-se o caráter absoluto do tempo e do espaço e, conseqüentemente, perderam sentido os pontos de vista privilegiados e a ideia clássica de simultaneidade. O ser humano soube que, embora se aproximasse muito rapidamente de um feixe de luz, nunca poderia alcançá-lo e - surpresa maior - que a velocidade da radiação luminosa sempre teria a mesma magnitude, mesmo que fossem alteradas a direção e a rapidez do agente medidor. A gravidade passou a ser explicada em função das deformações curvas causadas pelos corpos astronômicos de grande dimensão, fato que deu maior visibilidade e aplicabilidade aos sistemas geométricos não-euclidianos. Também foi detectado que o vínculo entre matéria e energia era mais forte do que se pensava, a ponto de ser identificada uma relação de equivalência entre essas entidades (descoberta que mudou drasticamente o rumo da história). Pouco tempo depois, o mundo subatômico mostrou características que o diferenciavam substancialmente do universo cósmico, fazendo dele uma realidade mutante, instável e, em boa medida, imprevisível. O homem, na sua escala macroscópica, passou a não se reconhecer mais como centro, mas como parte indissociável dessa realidade. Ele soube, então, que suas ações afetariam, inevitavelmente, a própria natureza física, 
e que esta não poderia ser compreendida se ele assumisse a neutra posição de um espectador. (LÉVY-LEBLOND, 2004).

À medida que as descobertas científicas se estendiam além dos círculos especializados, foi mudando a idéia que tínhamos da Natureza; especialmente, a imagem de sua constituição fundamental e do seu comportamento. A repercussão dos novos conhecimentos sentiu-se especialmente na obra de escritores e artistas plásticos, que se viram estimulados por uma realidade completamente nova, exposta pela ciência de maneira abstrata - realidade que pedia para ser explorada de todos os ângulos e com diversas linguagens. Não foram poucos os casos em que as ideias divulgadas pelos cientistas em suas teorias revolucionárias se conjugaram harmoniosamente com a visão dos artistas, reforçando os argumentos dos que procuravam maneiras inovadoras de compreender o mundo. Para alguns, a confiança nas verdades científicas foi determinante na adoção de vias sistemáticas na atividade criativa, na assunção de parâmetros estéticos análogos aos valores da ciência e na conformação de linguagens híbridas onde elementos e conceitos provenientes de vários domínios pudessem conviver amigavelmente.

A marca da ciência foi particularmente notável nas manifestações artísticas de cunho construtivista e em suas ramificações (conjunto que inclui uma boa parte da arte cinética), cujos protagonistas demonstraram mais interesse pela estrutura e a dinâmica do universo físico do que por sua aparência figurativa. Desde as obras pioneiras, os artistas construtivos valorizaram o espaço como sendo parte integral dos corpos e não simplesmente um cenário onde estariam localizados. Questionaram a postura tradicional que via massa e volume como sinônimos e afirmaram que tempo e movimento não podiam continuar sendo trabalhados plasticamente através de imagens estáticas, mas como realidades que deveriam manifestar-se na própria obra. (GABO, 1999a) (GABO, 1999b). A ciência fortaleceu a convicção de muitos artistas construtivistas e cinéticos de que o mundo funcionava como uma imensa estrutura regida por ritmos dinâmicos, e que para aproximar-se desse complexo sistema seria estritamente necessário incorporar a dimensão temporal.

Considerado um dos pioneiros da arte cinética, o venezuelano Jesús Soto ${ }^{1}$ (1923-2005) desenvolveu um trabalho sistemático de pesquisa que o conduziu a problemas que extrapolam o domínio da arte. O estudo da sua obra revela a trajetória de um investigador incansável do movimento, da 
luz, do espaço e da energia, que abordou a fenomenologia do mundo físico com aguda sensibilidade artística, sem perder de vista o que a ciência tinha para dizer sobre as dimensões cotidianamente inatingíveis.

Os objetos cinéticos criados por Soto se aproximam do dinamismo característico da Natureza, sem reproduzi-lo ou representá-lo. A maneira como trata os elementos de expressão plástica e a clareza de suas ideias refletem uma aguda assimilação e um estudo profundo da essência ontológica do universo físico e de suas expressões energéticas. Soto explora o movimento, não como um fenômeno exclusivamente corporal, mas como uma manifestação sutil da energia universal, e encontra nos elementos plásticos mais simples um meio ideal para dizer-nos que somos parte ativa desse Universo, de sua dimensão substancial. Usando um vocabulário próprio, o artista venezuelano diversifica as possibilidades da linguagem cinética, sensibilizando a rigidez da geometria, até fazer com que o homem possa "traspassá-la" e tornar-se parte dela. Trabalhando com efeitos ópticos que em outros artistas são ferramentas visuais de extrema dureza, Soto acentua a dimensão lúdica da fruição, transmitindo uma grata sensação de liberdade ao espectador-participante.

Existem vínculos importantes entre a produção artística de Soto e os conhecimentos gerados pela ciência nos últimos cem anos de história, bem como relações significantes com os modos de pensamento e os procedimentos característicos do espírito científico, os quais foram paradigmáticos para o artista sul-americano. Para Soto, a arte é um meio de conhecimento que deve "avançar dialeticamente", como acontece com a ciência. Essa postura manifesta-se em três aspectos centrais do seu processo artístico:

1. Na colocação de novos problemas, que - de acordo com Soto - devem "acompanhar" as interrogantes de sua época.

2. Na renovação das linguagens plásticas, necessária para poder abordar "corretamente" os problemas expostos.

3. Na reformulação do trabalho do artista, que, em sua opinião, deve passar a agir, basicamente, como um pesquisador.

Soto reflete assiduamente sobre a estrutura do Universo e as leis que o regem. Sente a necessidade de compreender os fenômenos naturais fundamentais, tanto em uma escala cósmica como subatômica. Para isso, serve-se de teorias científicas, por considerá-las as referências mais objetivas e universais. Acredita firmemente que a especulação no campo das ciências contemporâneas pode "dialogar" 
sem problemas com as pesquisas plásticas, ampliando assim o conhecimento do mundo que nos rodeia.

Dentre todas as áreas da ciência, a matemática e a física são as disciplinas que Soto prefere assumir como paradigmas e pontos de referência para sua obra, ressaltando nelas seu alto nível de abstração e a universalidade dos seus conteúdos. Seguindo as colocações de Gaston Bachelard, o artista reconhece nos novos sistemas geométricos e nas ideias introduzidas pelas físicas relativista e quântica, as mudanças mais radicais e significativas vividas pelo conhecimento científico durante o século XX. É por isso que coloca essas teorias no eixo central de suas disquisições, atraído pelo caráter altamente inovador das proposições. Entretanto, é importante notar que essas teorias também são legitimadoras de um pensamento hermético e afastado do mundo cotidiano e dos nossos atos mais práticos. Merleau-Ponty (1964, p.159) explica que, quanto mais teórico é o domínio de uma disciplina (como ocorre na matemática e na física contemporâneas), mais os objetos do conhecimento são tratados como "objetos-em-geral", quer dizer, como entidades abstratas sobre as quais se aplica um pensamento regrado e operacional.

Os novos saberes sobre a realidade física formulados no início do século XX colocaram em evidência cisões fundamentais entre o que conhecemos do mundo mediante os nossos sentidos e experiências e o que conhecemos do mundo por meio do pensamento científico abstrato. Nunca antes os pesquisadores haviam entrado em choque tão frontal com as noções clássicas de tempo, espaço e causalidade: formas a priori da sensibilidade que, segundo Kant, surgem antes de qualquer tipo de experiência e, portanto, seriam absolutas. Tais noções foram tradicionalmente aceitas e se arraigaram fortemente durante séculos, dentre outros motivos, porque não entravam em contradição com as nossas vivências mais comuns. A ciência contemporânea introduziu então novas definições que chegaram a causar um impacto excepcional, basicamente por serem alheias ao domínio empírico do ser humano.

Como trabalhar plasticamente com noções tão abstratas; tão afastadas do mundo sensível? Soto, ciente do papel que sua obra podia desempenhar na compreensão integral desse mundo, propõe uma arte estreitamente associada ao corpo, às suas relações com o entorno e às singularidades da percepção, com a intenção de complementar, em um plano sensível, o que a ciência transmite racionalmente (com limitações) sobre o mundo que nos rodeia. Dessa maneira, atuando conjuntamente, arte e 
ciência cumpririam uma função didática, formativa e, até poderíamos dizer, "reveladora" da complexa realidade do Universo.

Na opinião de Soto, a arte permite que estabeleçamos com o mundo relações que a ciência não consegue (nem pretende) estabelecer, e que captemos fatos que a ciência não sabe (nem deseja) expressar. Abrangendo domínios amplos, que vão do terrestre ao sublime, do racional ao emocional, do conceitual ao prático e do comprometido ao lúdico, a arte atua com a liberdade e a expansividade que lhe são inerentes, para construir pontes inéditas com uma determinada realidade. A ciência, por sua vez, pode ser uma aliada da arte - assim o entende Soto -, ao revelar associações desconhecidas entre entidades que estão fora do alcance dos nossos sentidos, ao aprofundar e ir além do que o senso comum e a vivência cotidiana nos ensinam, e ao enriquecer o imaginário com descrições sempre renovadas de fenômenos e estruturas. Soto acredita que o diálogo recíproco e sem prejuízos entre arte e ciência só pode ter como resultado o enriquecimento da nossa compreensão dos acontecimentos do mundo.

Em Soto há uma atitude otimista em relação ao papel que a arte e a ciência podem desempenhar conjuntamente, no avanço do conhecimento. Ele acredita firmemente que toda e qualquer linguagem usada para entender e representar o mundo devolverá aproximações parcialmente satisfatórias, em razão de suas próprias limitações expressivas e da constituição mesma do mundo físico - este último, impossível de ser decifrado com total certeza, conforme o demonstrado por Werner Heisenberg (1999, p. 47 et seq.). A confiança de Soto na ciência, como fonte informativa e metodológica para desvendar essa complexa realidade, acopla-se harmoniosamente com seu desejo de transmitir um conhecimento objetivo, mediante imagens de alcance universal, que possam ser apreendidas por todos. Paralelamente, sua confiança na arte apóia-se na capacidade que ela tem de criar novas experiências sensoriais, perceptivas, e de inseri-las no universo de nossas vivências cotidianas, comunicando conceitos e ideias difíceis de apresentar com outras linguagens. A arte - pensa Soto - pode nesses casos instaurar ligações com a realidade física, muito mais aguçadas e tangíveis que aquelas que consegue estabelecer a própria ciência; em particular a ciência contemporânea, cheia de abstrações e exígua em modelos visuais.

Soto percorre linhas de trabalho vinculadas a problemas tratados pelas ciências nas primeiras décadas do século XX. Dentre elas, sobressai o estudo das relações e transformações entre a matéria e a energia. A relevância dada a esse 
assunto e a persistência com que Soto retorna uma e outra vez a esse problema, fazem dele uma espécie de coluna vertebral que percorre e sustenta grande parte da trajetória do artista, manifestando-se com força desde as etapas iniciais até as últimas criações. Em algumas obras, Soto explora a dinâmica que ganham os corpos físicos quando apresentados sob determinadas condições ópticas que afetam sua solidez aparente. Em outras, reduz progressivamente a materialidade desses corpos até levá-los a um estado limite, no qual o que resta são intensas vibrações que contagiam o entorno. Também há casos em que o artista constrói figuras volumétricas a partir de materiais tão finos e transparentes que mais parecem fios de luz. Em todas essas situações há sempre um vaivém entre o matérico e o energético, entre o rígido e o fluido, entre o manifesto e o etéreo. $\mathrm{O}$ estudo da obra de Soto confirma a coerência com que foi conduzida essa linha de trabalho e permite identificar diversos pontos de vista a partir dos quais o artista focaliza a sua pesquisa; o que, por sua vez, nos leva a reavaliar historiograficamente uma etapa particular de sua produção (correspondente às obras realizadas no início da década de sessenta), tratada, por vários especialistas, como um momento isolado e virtualmente desligado do conjunto. Como alternativa, propomos uma leitura diferente da obra deste artista, menos ligada a critérios estilísticos e formais, e mais relacionada com as inquietações sobre os fenômenos do mundo físico.

A Física Relativista e a Teoria Quântica também foram fontes de enorme valor para que Soto refletisse profundamente sobre as dualidades presentes na Natureza; dentre elas a dualidade da luz, cujo comportamento, sabemos, pode manifestar-se ondulatória e corpuscularmente. $\mathrm{O}$ mundo plástico de Soto mostra abertamente sua própria natureza dual a partir do momento em que integra, em um mesmo locus (a obra), a pulsação de elementos discretos (pontos, linhas, quadrados etc.) com a irradiação que emana do conjunto desses elementos, apreendidos como um todo contínuo. É por isso que a imagem de suas obras flutua entre o palpitar pontual e a ondulação global - estados que, na mão de Soto, deixam de se confrontar como opostos, para atuarem integradamente. As lições de Niels Bohr (1995, p.94) e a Teoria Quântica estão presentes na maneira como o artista manipula características aparentemente excludentes de uma mesma entidade, e as apresenta não mais como contraditórias e sim como complementares. $\mathrm{O}$ caso das chamadas figuras "virtuais" exemplifica o permanente (e nunca conclusivo) estado de formatividade 
em que se encontram as imagens de Soto, sempre titubeando entre o atual e o potencial. Nesse tipo de trabalho, teve um papel fundamental o legado de Naum Gabo e, posteriormente, o de László Moholy-Nagy com seus corpos cinéticos fabricados a partir de transparências, movimento e luz.

Dual, ambíguo e indivisível é também o continuum espaço-tempo que desperta tanto interesse em Soto e nos físicos relativistas. (EINSTEIN, 1999). A maior parte de suas obras se concentra na impossibilidade de apreender a unidade espaço-temporal de um único ponto de vista ou em apenas um instante, sublinhando, igualmente, quão inadequado seria defender seu caráter absoluto. Bem informado das mudanças sofridas pelo espaço plástico durante os últimos oitenta anos, e já conhecedor dos aspectos mais relevantes da revolução einsteiniana, o Soto dos anos sessenta deu passos importantes para concretizar sua própria interpretação dessa complexa realidade. (SOTO, 1993). Progressivamente, chega à conclusão de que trabalhar o movimento no espaço, e não através do espaço, é uma maneira efetiva de fundir a dimensionalidade espacial e a temporal. Ele o consegue ativando esse vazio aparentemente mudo que gravita nas obras, fazendo dele uma entidade elástica, mutável e vibrante; isto é, convertendo-o em movimento mesmo. Para isso, serve-se do poder das transparências e do efeito moiré que, combinados, fazem com que percamos a medida exata da profundidade e a distinção absoluta entre figuras e fundos.

Quando a Física Quântica demonstrou que o ato de observação pode modificar o fenômeno observado e que, portanto, o que nos chega não são os fatos "puros" senão os resultados da nossa interação com os mesmos, estava sendo colocado ponto final em uma larga tradição do pensamento científico ocidental que estabelecia uma separação estrita entre o mundo, como objeto de conhecimento, e o homem, como sujeito conhecedor. (HEISENBERG, 1999, p.85). A descrição newtoniana da Natureza e sua sucessora, a teoria relativista de Einstein, assumiam como ponto de partida que a realidade era independente do método e dos procedimentos usados para investigá-la. No entanto, o olhar quântico sobre o mundo subatômico mostrou que a exploração empírica do entorno nos inclui forçosamente e que as conseqüências desse contato também são parte da realidade estudada. Soto, desejoso de criar vias efetivas para conhecer o mundo físico através de meios sensíveis, mostra que compartilha a lição quântica ao fazer do fruidor o elemento fundamental da performance cinética: 
Antigamente, o espectador situava-se como uma testemunha exterior à realidade. Hoje nós sabemos bem que o homem não se encontra de um lado e o mundo de outro. Não somos observadores, mas partes constituintes de uma realidade fervilhante de forças vivas das quais muitas são invisíveis. Estamos no mundo como peixes na água: sem recuo frente à matéria-energia; dentro não em frente de; não existem mais espectadores, existem apenas participantes. (Soto apud PIERRE, [s.n.p.])

Em sintonia com os valores usados pela ciência contemporânea, Soto dá mais relevância às relações entre as entidades do que às entidades mesmas. Recordemos que já no século XIX, as geometrias não-euclidianas provaram que, muito mais importante do que estabelecer axiomas ou conceitos absolutos, era construir relações coerentes entre os elementos basilares de um sistema de conhecimentos. (DALRYMPLE, ca. 1983). Einstein corrobora, anos depois, a impossibilidade de conhecer entidades isoladas na Natureza, visto que existem relações que as aproximam, a ponto de fusioná-las e modificá-las ontologicamente. Para o artista venezuelano, o fenômeno do movimento, no qual estão envolvidas várias entidades (tempo-espaço, matéria-energia), pode ser trabalhado na obra de arte, manipulando, testando e variando as relações entre os elementos de expressão plástica: quer dizer, experimentando com o dinamismo das relações cromáticas, de tamanho, de densidade etc., mas nunca dissecando-o em um dos seus instantes. Aqui é importante ressaltar que o dinamismo dessas relações se manifesta necessariamente através do tempo, e não em instantes isolados. Critérios como estes reforçam a visão dinâmica que Soto tem do Universo e sua convicção de que a obra cinética é a via "mais adequada" para trabalhar, no plano artístico, com essa realidade essencialmente relacional.

Ao privilegiar as relações sobre os elementos, Soto demonstra seu interesse nos aspectos estruturais da obra. $\mathrm{O}$ trabalho organizado por séries lhe permite explorar diversas distribuições dos elementos de expressão formal e as conseqüências de cada organização no comportamento da totalidade. Assim, cada componente, vista por separado, não lhe parece tão significativa quanto o papel que essa parte desempenha dentro do conjunto global. A reiteração de certas formas geométricas, como o quadrado, poderia levar-nos a supor que o artista desejava exaltar essas figuras per se. Contudo, uma análise da sua obra mostra que a repetição insistente 
dos signos plásticos cumpre o objetivo de reduzir ao máximo a individualidade dos mesmos e de dar visibilidade à maneira como eles se vinculam com o entorno. Entre os recursos usados por Soto para gerar um espectro amplo de estruturas, controlando ao máximo sua própria subjetividade, estão algumas relações matemáticas (como a progressão e a permutação) e certos procedimentos aleatórios inspirados nas técnicas usadas pela música dodecafônica. Soto se vale de fórmulas e codificações de natureza extra-plástica para submeter sua criação a um controle que, mesmo sendo racional, dá espaço ao inesperado e ao casual. Com suas próprias palavras:

No início fazia coisas estruturadas empregando elementos geométricos. Em seguida, tentei fazer evoluir essa geometria em direção a uma escrita mais livre. [...] Antes realizava o quadro como uma coisa previsível, pré-concebida. No entanto, mais tarde, vim valorizar, na realização das minhas obras elementos de encontro e de acaso. [...] Para mim, o acaso é o elemento vivo que causa um tipo de surpresa. (Soto apud PIERRE, [s.n.p.])

Soto consegue alcançar assim um delicado equilíbrio entre a rigorosidade da imagem programada e o caráter imprevisto e muitas vezes sutil da livre espontaneidade; uma mescla que Damián Bayón e Aldo Pellegrini caracterizaram com o termo "geometria sensível", querendo adjetivar o tratamento construtivista menos severo que possibilita o encontro entre a intuição lírica e o rigor geométrico, sem o abandono do exercício da razão, subjacente a toda criação de corte lógico-matemático.

A produção organizada por séries também responde a uma necessidade de experimentação do artista, que se sente como um verdadeiro pesquisador da imagem, da sensorialidade humana e da realidade natural que nos envolve. A dúvida, atitude tipicamente científica e experimental, manifesta-se com força em dois níveis da produção de Soto. Por um lado, na maneira curiosa e crítica como ele mesmo se coloca perante os fatos que vai descobrindo à medida que avança em sua pesquisa plástica. Cada problema trabalhado por Soto não se transforma em um problema resolvido ou encerrado, mas sim na semente de novos problemas, de novas inquietações. As linhas de pesquisa trabalhadas se renovam e diversificam, em vez de estabilizar-se ou de acomodar-se ao redor de pontos fixos. Sobretudo depois do fim dos anos sessenta, observa-se um intenso movimento de ramificação nos 
problemas abordados, os quais respondem a indagações que se transformam e reformulam movidas por uma curiosidade em franca expansão. Inclusive, já avançada sua produção, efetuam-se cruzamentos muito interessantes entre séries que pareciam estar atingindo um estado de esgotamento (ex. as obras derradeiras intituladas Sínteses).

Em casos como o das obras do início dos anos sessenta (tradicionalmente reunidas sob a categoria de "barrocas"), Soto submete a prova uma "hipótese", testando-a em condições extremas, com a intenção de avaliar o amplo leque de conseqüências. Não se conforma em seguir o caminho que até então vinha "funcionando" satisfatoriamente (o da geometria estrita), e prefere questionar, indagar e abordar outras possibilidades que nesse momento lhe parecem menos óbvias. Já dizia Gaston Bachelard que as verdades "óbvias" são obstáculos para o estudo objetivo de qualquer fenômeno, e que a dúvida recorrente é muito mais produtiva para o avanço do conhecimento. Em opinião do filósofo francês, um autêntico pensamento criador é aquele que submete à crítica as verdades aparentes. (BACHELARD, 1991).

Por outro lado, Soto induz a dúvida no próprio fruidor, ao colocá-lo em contato com situações perceptivas ambíguas que demandam atenção e despertam sua curiosidade. Dessa maneira, o artista faz do ato de fruição um encontro aberto e sempre renovado entre o ser humano e uma porção da realidade física que permanece - e permanecerá - sem explicação. Penetráveis, Vibrações e Cubos Ambíguos redobram nosso interesse nas imprecisões do mundo fenomênico, fazendo-nos mais cientes das incertezas que permeiam sua leitura. É nesse sentido que podemos dizer que a obra de Soto estimula o olhar científico sobre o mundo; isto é, a observação atenta e inquisitiva, que não se satisfaz consigo mesma nem com explicações imediatas ou elementares.

$\mathrm{O}$ acesso de Soto aos conhecimentos que revolucionaram o curso da ciência contemporânea efetivou-se por vias múltiplas e de distinta natureza. Nesse processo, ocupou um lugar especial a epistemologia de Gaston Bachelard, por esclarecer o papel que tiveram as geometrias não-euclidianas e os sistemas quântico e einsteiniano na apreensão não-cartesiana do mundo físico. O filósofo francês não oferece explicações sobre as teorias em si, mas sim sobre a significação delas na reformulação dialética do conhecimento e na criação de novos métodos para conhecer a Natureza. Dos textos desse autor, é possível que Soto tenha extraído uma ideia clara de como mudou a noção de Realidade até então 
adotada pela ciência e de como mudaram seus critérios de verdade, objetivos e princípios. O próprio artista chegou a afirmar que o contato com as ideias de Bachelard lhe deu a motivação suficiente para se dedicar ao estudo específico das teorias científicas; fato que se concretizou com a ajuda de amigos físicos e matemáticos com os quais Soto trocou ideias e estabeleceu longas e proveitosas discussões. (JIMÉNEZ, 2001). Sabemos, também, que o venezuelano teve acesso a textos escritos pelos próprios cientistas (dentre eles, Heisenberg e Bohr), cujo conteúdo chegou a citar textualmente e a interpretar livremente em ocasião de entrevistas, conferências e conversas informais. É interessante recordar que esses cientistas deram valor à divulgação de suas teorias e que alguns deles redigiram textos menos herméticos para explicá-las ao público leigo. Soto também se alimentou daquilo que os grandes mestres da arte moderna (especialmente Naum Gabo e László Moholy-Nagy) tinham para dizer sobre a ciência, seus conhecimentos e suas verdades, em uma linguagem que deve ter lhe resultado muito mais familiar. (MOHOLY-NAGY, 1946) (MOHOLY-NAGY, 1972). A atitude aberta à experiência e à experimentalidade, a aceitação da matemática como recurso para gerar e organizar a imagem, a incorporação de fatores aleatórios na performance da obra e na sua fruição e a exploração de relações dinâmicas entre os elementos plásticos são alguns dos eixos de referência, oferecidos por esses mestres, que Soto adota e incorpora em sua própria obra, com a confiança de quem quer estender pontes fecundas entre a arte e a ciência. Finalmente, não podemos deixar de assinalar o ambiente estimulante que Soto compartilhava com outros "pesquisadores plásticos" concentrados em problemas similares - como foi o caso de Yves Klein; alguns deles interessados nas teorias científicas mais recentes e dispostos a intercambiar seus pontos de vista, críticas e colocações. Com eles houve uma troca de ideias sobre como trabalhar com uma realidade física cuja imagem fora radicalmente modificada pela ciência contemporânea.

Entendo por metafísica a física que aguarda demonstração. Estes caminhos não estão muito afastados das preocupações caras à ciência contemporânea sobre a incerteza no conhecimento da estrutura microscópica. Sempre aproximei esta angústia essencial da concepção de 'vazio' em Yves Klein, da de 'cheio' em Armand e da determinação de Lúcio Fontana, quando este cria, com as suas lacerações, o espaço pluri-dimensional na bidimensionalidade da tela. (SOTO, 1993, p. 151) 
Uma das posições que Soto assume com maior conviç̧ão é que a arte desempenha um papel transcendental na geração e divulgação do conhecimento. Mais ainda, que a arte é, em si mesma, conhecimento. A imagem do mundo que a arte ajuda a construir - especialmente a arte de Soto - parte de vivências empíricas tanto quanto de verdades teóricas. Para ele, pensamentos e sensações são duas fontes informativas muito valiosas que, ao se entrelaçarem, conseguem moldar - com bastante completitude, em sua opinião - uma visão plausível do Universo do qual fazemos parte. As realidades reveladas pela ciência contemporânea, sobretudo pela Teoria da Relatividade e a Física Quântica, são realidades abstratas, em extremo complexas, e que, na maioria das vezes, são descritas pelos especialistas apenas mediante expressões algébricas, codificações, matrizes numéricas e outras formulações que dificilmente conseguimos visualizar. Como apreender então, em sua mais ampla significação, as ideias trabalhadas pela física de partículas? Como incorporar no nosso imaginário os elos entre tempo e espaço, matéria e energia, rubricados pela Teoria da Relatividade?

Soto tenta dar as respostas, transladando ao plano sensível o que a razão não consegue expressar de uma maneira acessível para todos. Para isso, cria, com meios plásticos, metáforas da realidade física que chegam à obra respaldadas tanto pela razão científica como por suas próprias experiências artísticas: imagens, que ao serem ambíguas para a percepção, nos falam da impossibilidade de apreendermos absolutamente o mundo que nos rodeia; movimentos sem locus específico, que ao invadir o ambiente colocam em destaque o dinamismo intrínseco da dimensão espaço-temporal; objetos que aparecem e desaparecem ante os nossos olhos atônitos, evidenciando as trocas entre matéria e energia; estruturas que se comportam como campos sensíveis, mostrando o efeito de ações diretas e à distância; pulsos compassados e ondas que se dispersam, coabitando harmoniosamente em corpos fabricados de luz. Vivenciamos assim situações que se aproximam tangencialmente de certos fenômenos naturais que estão fora do nosso alcance perceptivo, da nossa experiência cotidiana e muitas vezes até da nossa imaginação.

Soto nos mostra como é possível reduzir as distâncias entre os estudos científicos e as pesquisas no campo artístico, ao revelar que ambos os corpos de conhecimento podem atuar de forma complementar na busca de respostas para os nossos questionamentos, persistentes e inesgotáveis, sobre a realidade do Universo. Sem sombra de dúvida, arte e ciência 
são duas manifestações complexas e profundas do espírito humano, que não podem ser apresentadas como conflitantes ou contraditórias. Justamente, por serem tão diferentes seus domínios conceituais, seus recursos e seus métodos, é que a ação conjunta pode ser tão fecunda e reveladora. Foi o que Soto intuiu, pôs em prática em sua obra plástica e traduziu no seu posicionamento perante a atividade criativa.

\section{Dados biográficos de Jesús Rafael Soto}

Fontes: (BOULTON, 1973) e (JIMÉNEZ, 2001)

Jesús Rafael Soto nasceu em Ciudad Bolívar, Venezuela, no ano de 1923. Ali recebeu instrução artística em nível elementar. Em 1942, viajou a Caracas e ingressou na Escola de Artes Plásticas, onde teve os primeiros contatos com reproduções de obras de Cézanne, Van Gogh e Braque, dentre outros. Concluiu o curso em 1947 e formou-se como "Maestro de Arte Puro". No mesmo ano foi chamado para exercer a direção da Escola de Artes Plásticas de Maracaibo, a segunda cidade mais importante do país. Em 1950, sentiu a imperiosa necessidade de viajar a Paris, onde conheceu e estudou as obras dos mestres da arte moderna, em especial dos abstratos, construtivistas e neoplasticistas. Desde essa data, deu início às suas experiências óticas: composições dinâmicas, progressões, repetições, obras seriais etc. Foi um dos protagonistas do nascimento da arte cinética, ao lado de Jean Tinguely, Jaacov Agam, Pol Bury, Victor Vasarely e outros. Em 1955, participou da exposição emblemática do cinetismo: "Le Mouvement", na Galeria Denise René. A partir desse momento, a obra de Soto esteve presente em importantes mostras internacionais, como a "Exposição do Movimento" em Amsterdam (Bewogen Beweging) em 1961, a Bienal de São Paulo de 1963 (premiado) e a Bienal de Veneza, em 1964 (premiado) e em 1966.

Durante sua trajetória artística, Jesús Soto abordou os temas do movimento, a imaterialidade na obra plástica, a incorporação ativa do espectador e a vibração da luz. Suas obras cinéticas ocupam espaços públicos em várias cidades da América Latina e do mundo. Dentre elas cabe ressaltar as estruturas cinéticas espalhadas pela cidade de Caracas, o mural da UNESCO em Paris, a ambientação da Fábrica da Renault, o volume virtual do Centro Pompidou, os penetráveis em vários países da Europa e da Ásia, as esferas e cubos virtuais em diversas coleções etc. Em 1973 foi fundado na sua cidade natal o Museu de Arte Moderna Jesús Soto, dedicado à exibição de 
obras nacionais e internacionais de tendências modernas e contemporâneas, e em particular da obra do próprio artista.

Soto falece no dia 14 de janeiro de 2005 em Paris. Poucos dias depois é inaugurada a exposição "Soto: a construção da imaterialidade" no Centro Cultural Banco do Brasil, no Rio de Janeiro, com curadoria de Paulo Venancio Filho.

\section{Referências bibliográficas}

BACHELARD, Gaston. A formação do espírito científico: contribuição para uma psicanálise do conhecimento. Rio de Janeiro: Contraponto, 1996.

O novo espírito científico. 6 ed., Rio de Janeiro:

Francisco Alves, 1991.

BOHR, Niels. A unidade do conhecimento. In: Física atômica e conhecimento humano: ensaios 1932-1957. Rio de Janeiro: Contraponto, 1995. p. 85-104. (Discurso proferido na Universidade de Columbia, New York, 1954).

BOULTON, Alfredo. Soto. Caracas: Armitano, 1973.

DALRYMPLE HENDERSON, Linda. The fourth dimension and non-Euclidean geometry in modern art. Princeton (USA): Princeton University Press, 1983.

EINSTEIN, Albert. A teoria da relatividade especial e geral. Rio de Janeiro: Contraponto, 1999.

GABO, Naum. Escultura: a talha e a construção no espaço. In: CHIPP, H.B. Teorias da arte moderna. São Paulo: Martins Fontes, 1999a, p. 333-341.

. O manifesto realista. In: CHIPP, H.B. Teorias $d a$ arte moderna. São Paulo: Martins Fontes, 1999b, p. 329-333.

HEISENBERG, Werner. Física e filosofia. 4 ed., Brasília: Universidade de Brasília, 1999.

JIMÉNEZ, Ariel. Conversaciones con Jesús Soto. Caracas: Fundación Cisneros, 2001. (Colección Patricia Cisneros, Cuaderno 6).

LÉVY-LEBLOND, Jean-Marc. O pensar e a prática da ciência: antinomias da razão. Bauru: EDUSC, 2004.

MERLEAU-PONTY, Maurice. Eye and mind. In: The primacy of perception and other essays on phenomenological psychology, the philosophy of arts, history and politics. [s.l.]: Northwestern University Press, 1964, p. 159-190.

MOHOLY-NAGY, László. La nueva visión. In: La nueva visión y reseña de un artista. Buenos Aires: Infinito, 1972, p. 8-120. (Primeira edição 1944). 
. Vision in motion. 3 ed., Chicago: Paul Theobald, 1946.

PIERRE, Arnauld. Cronologia. In: Soto (Catálogo de exposição). Paris: Jeu de Paume, 1998.

SOTO, Jesús. O papel dos conceitos científicos na arte. In: Soto: Retrospectiva (Catálogo de exposição). Porto: Fundação de Serralves, maio-jul. 1993, p. 145-152.

\section{NOTAS}

1. Para maiores detalhes da vida de Jesús Soto, vide o informativo biográfico. Para visualizar imagens das obras do artista, recomendamos o site oficial: http://www.jr-soto.com

Recebido em: 03/08/10

Aceito em: 27/09/10

\section{MARIELA BRAZÓN HERNÁNDEZ}

marielabrazon@yahoo.com.br

Doutora em Artes Visuais e professora adjunta da Escola de Belas Artes da Universidade Federal da Bahia. 